\title{
Polymorphisms in the HOXD4 gene are not associated with peak bone mineral density in Chinese nuclear families
}

Hao ZHANG, Jin-wei HE, Gao GAO, Hua YUE, Jin-bo YU, Wei-wei HU, Jie-mei GU, Yun-qiu HU, Miao LI, Wen-zhen FU, Yu-juan LIU, Zhen-lin ZHANG*

Department of Osteoporosis and Bone Diseases, Metabolic Bone Disease and Genetic Research Unit, Shanghai Jiao Tong University Affiliated Sixth People's Hospital, Shanghai 200233, China

\begin{abstract}
Aim: To determine the associations between HOXD4 gene polymorphisms with peak bone mineral density (BMD) throughing measuring three tagging single nucleotide polymorphisms (tagSNPs), including rs1867863, rs13418078, and rs4972504, in HOXD4.

Methods: Four hundred Chinese nuclear families with male offspring (1215 subjects) and 401 Chinese nuclear families with female offspring (1260 subjects) were recruited. BMD of the lumbar spine 1-4 (L1-4) and left proximal femur including total hip and femoral neck were measured by dual-energy X-ray absorptiometry. The quantitative transmission disequilibrium test (QTDT) was performed to investigate the association among the tagging SNPs, haplotypes and peak BMD.

Results: Only the CC genotype was identified in rs13418078 in the Chinese population, unlike other populations. We failed to find significant within-family association among these SNPs, haplotypes and peak BMD at any bone site in either male- or female-offspring nuclear families.

Conclusion: The results suggest that genetic polymorphisms in HOXD4 may not be a major contributor to the observed variability in peak BMD in the lumbar spine and the hip in Chinese men and women.
\end{abstract}

Keywords: peak bone mineral density; HOXD4; single nucleotide polymorphism; quantitative transmission disequilibrium test

Acta Pharmacologica Sinica (2010) 31: 977-983; doi: 10.1038/aps.2010.91

\section{Introduction}

Osteoporosis is characterized by a reduced strength of bone structure and an increased risk of fracture. The etiology of osteoporosis is determined by both genetics and environment. A number of prospective studies have demonstrated that bone mineral density (BMD) is one of the best predictors of a future fracture $^{[1]}$. Although several environmental factors influence BMD, genetic factors account for $60 \%-80 \%$ of BMD variability $^{[2,3]}$.

Genome-wide association studies have been facilitated by the HapMap project, and several whole genome linkage scans have been conducted on $\mathrm{BMD}^{[4,5]}$. Chromosomal locus $2 \mathrm{q} 32$ showed a suggestive linkage with both hip and wrist BMD phenotypes ${ }^{[6]}$. Our previous study identified genetic polymorphisms in myostatin which is located in this region and likely promotes the attainment of peak BMD in Chinese women ${ }^{[7]}$. The homeobox D (HOXD) gene family is also located within

\footnotetext{
* To whom correspondence should be addressed. E-mail ZZL2002@medmail.com.cn

Received 2010-03-11 Accepted 2010-06-17
}

this region ${ }^{[8]}$. Prior to bone formation, these HOXD genes play a central role in regulating cartilage differentiation and osteoblast gene expression ${ }^{[9]}$. Li et al ${ }^{[10]}$ hypothesized that HOXD proteins play an important role in the bone morphogenetic protein (BMP) pathway. HOXC8, a member of the HOX family, acts as a repressor of the BMP pathway. Transgenic mice that overexpressed the Smad1 interaction domain of HOXC8 had higher bone density compared with their littermates ${ }^{[11]}$. Overexpression of HOXD4 results in severe cartilage defects similar to the phenotype elicited by overexpression of $\mathrm{HOXC8}$, indicating comparable effects of HOXD4 and HOXC8 on chondrocyte differentiation ${ }^{[12]}$. Thus, we selected HOXD4 as a candidate gene that may be involved in osteoporosis. Oliver et $a l^{[13]}$ found by in situ hybridization that HOXD4 was localized to $2 \mathrm{q} 31-\mathrm{q} 32$, with a peak number of gains at $2 \mathrm{q} 32.3$. Mavilio et $a l^{[14]}$ reported that the HOXD4 gene may exert a wide spectrum of control functions in a variety of organs during early mammalian development. The HOXD4 gene maps to human chromosome 2 in the q31.1 region, and its total length is $1.839 \mathrm{~kb}^{[15]}$. Until now, no study has reported an association between single nucleotide polymorphisms (SNPs) of the HOXD4 gene 
and BMD in humans. The majority of the association studies between genotypes and BMD have been performed in women $^{[7,16-20]}$. Therefore, we recruited two cohorts of nuclear families where one cohort contained only male offspring and the other cohort contained only female offspring. We investigated the association among SNPs, haplotypes in the HOXD4 gene and peak bone mass in both men and women to avoid any confounding effect of gender on the results. Shanghai is a modern city inhabited by tens of millions of people from many Chinese ethnic groups; therefore, sample heterogeneity may be a problem ${ }^{[16]}$. However, the family-based association method quantitative transmission disequilibrium test (QTDT) is robust with regard to population stratification ${ }^{[21]}$. Therefore, we used nuclear families as our study population and performed QTDT to determine if tagging SNPs (rs1867863, rs13418078 and rs4972504) in the HOXD4 gene were associated with peak BMD variation in the spine and the hip in this relatively large sample of Chinese nuclear families.

\section{Materials and methods Subjects}

Between 2004 and 2007, we recruited 1296 individuals between 18 and 44 years of age from 427 male-offspring Chinese nuclear families composed of both parents and at least one healthy male child. Of the total group, 15 individual genotypes could not be amplified and discriminated due to poor quality DNA, and 12 sons deviated from Mendelian inheritance. Our study included only 400 male-offspring nuclear families with a total of 1215 individuals for subsequent analysis. The average family size was 3.04; 385 families had 1 child and 15 families had 2 children. Every study subject completed a questionnaire concerning age, sex, medical history and family history and all male offspring were healthy. The following criteria were used to exclude individuals of male-offspring families from the study: (1) serious residuals from cerebral vascular disease; (2) diabetes mellitus; (3) chronic renal disease; (4) serious chronic liver disease or alcoholism; (5) significant chronic lung disease; (6) corticosteroid therapy at pharmacologic levels for $>3$ months; (7) treatment with anticonvulsant therapy for $>6$ months; (8) evidence of other metabolic or inherited bone disease such as hyperparathyroidism or hypoparathyroidism, Paget's disease of the bone, osteomalacia and osteogenesis imperfecta; (9) rheumatoid arthritis or collagen disease; (10) recent major gastrointestinal disease (within the past year) such as peptic ulcer, malabsorption, chronic ulcerative colitis, regional enteritis, or any significant chronic diarrhea state; (11) significant disease of any endocrine organ that would affect bone mass; (12) hyperthyroidism; and (13) any neurological or musculoskeletal condition that would be a nongenetic cause of low bone mass.

We also recruited 1323 individuals from 422 female-offspring Chinese nuclear families composed of both parents and at least one healthy female child aged between 19 and 44 years from 2000 to 2002. We excluded 15 individuals whose DNA could not be amplified to discriminate genotype due to its poor quality, and 6 daughters who deviated from Mendelian inheritance. As previously reported, we ultimately acquired 401 integrated female-offspring nuclear families comprising 1260 individuals $^{[7,16-18]}$. The average family size was $3.14 ; 348$ families had one child, 50 families had two children, 2 families had three children, and 1 family had four children. Exclusion criteria were adopted as previously reported ${ }^{[7,16-18]}$.

All study subjects belonged to the Chinese Han ethnic group. Subjects were from a local Shanghai population living near the middle of the eastern coast of China. The study was approved by the Ethics Committee of the Shanghai Jiao Tong University Affiliated Sixth People's Hospital. All subjects involved in the study signed informed consent documents before joining the project.

\section{BMD measurements}

BMD $\left(\mathrm{g} / \mathrm{cm}^{2}\right)$ of the lumbar spine 1-4 (L1-4) and left proximal femur including total hip and femoral neck were measured by dual-energy X-ray absorptiometry (DXA). All subjects from the male-offspring nuclear families were measured with Lunar Prodigy equipment (GE Lunar Corp, Madison, WI, USA). The Lunar device was calibrated daily, and the coefficient of variability $(\mathrm{CV})$ values of the DXA measurements in L1-4, the total hip and the femoral neck were $1.39 \%, 0.70 \%$, and $2.22 \%$, respectively ${ }^{[22]}$. All subjects from the femaleoffspring nuclear families were measured using Hologic QDR 2000 equipment (Hologic, Bedford, MA, USA). The machine was calibrated daily. CV values of the DXA measurements at L1-4, total hip and femoral neck were $0.9 \%, 0.8 \%$, and $1.93 \%$, respectively ${ }^{[16,17]}$. The two types of nuclear families had BMD detected by two categories of DXA because we recruited the female- and male-offspring nuclear families in different years for different projects. Members of the same nuclear family were measured on the same machine; therefore, there was no effect due to different DXA measurement in our association analysis.

\section{Tagging SNP selection and genotyping}

A total of 9 NCBI tagging SNPs are present in HOXD4 (Gene ID: 3233), and an additional 16 tagging SNPs were found in the Applied Biosystems data source (http://www.genecards. org/cgi-bin/carddisp.pl?gene=HOXD4). Three of these tagging SNPs map to the 5'- or 3'-UTR, and the majority are proximal to the gene. Because the HOXD4 gene is small, only three tagging SNPs (rs1867863, rs13418078 and rs4972504) had minor allele frequencies (MAF) $>10 \%$ in the Japanese population, as demonstrated at the International HapMap Project Site (http://www.hapmap.org/cgi-perl/gbrowse/hapmap_B36/). In addition, according to the NCBI website (http://www. ncbi.nlm.nih.gov/projects/SNP/snp_ref.cgi?rs=13418078), "rs13418078" has MAF < 10\% (for T allele) in the European population.

Genomic DNA was extracted from peripheral blood samples using routine methods. Amplification and allelic discrimination were performed in an Mx3000P Real-Time PCR System (STRATAGENE, CA). One allelic probe was labeled with FAM dye and the other probe with HEX dye. Then, $20 \mathrm{ng}$ of 
genomic DNA was amplified on a 96-well plate in the presence of 1X TaqMan probe assay and 1X TaqMan Universal PCR Master Mix (Applied Biosystems). The PCR program included an initial cycle at $95^{\circ} \mathrm{C}$ for $10 \mathrm{~min}$, followed by 40 cycles at $95^{\circ} \mathrm{C}$ for $15 \mathrm{~s}$ and $60^{\circ} \mathrm{C}$ for $1 \mathrm{~min}$.

\section{Statistical analysis}

We used Haploview vision 3.2 $2^{[23]}$ to calculate Lewontin's $\mathrm{D}^{\prime}$ and the linkage disequilibrium (LD) coefficient $r^{2}$ values between all pairs of biallelic loci. Haplotypes of each individual were estimated by PHASE software (ver 2.0) using the algorithm developed by Stephens et al ${ }^{[24]}$. Genotype frequencies and haplotypes were calculated in comparison to the unrelated parents of nuclear families. The genotyping quality of every SNP was checked for Hardy-Weinberg equilibrium by a $\chi^{2}$ goodness-of-fit statistic. The heritability estimates were calculated using the linear regression of mean parental value and offspring value for every phenotype using SPSS version 11.0 (SPSS, Chicago, IL, USA) (this method was described at www.heritability.com). The power estimation was calculated by Piface software (version 1.65) (http://www.stat. uiowa.edu/ rlenth/Power/) for our current sample size, according to the MAF of every genotype and the variation of BMD genotypes. The QTDT program (available at http:/ / www.sph.umich.edu/csg/abecasis/QTDT/) was used to test for linkage, population stratification, total association and within-family association among SNPs, haplotypes and BMD phenotypes. The QTDT program extends the transmission disequilibrium test (TDT) to quantitative traits to construct a general approach that can accommodate nuclear families from siblings and parents ${ }^{[25,26]}$. The total family association may be influenced by population stratification; however, the withinfamily association is unaffected by population stratification and is significant only when linkage disequilibrium is present. In all statistical analyses, BMD values were adjusted by age, weight and height as covariates. We tested male- and femaleoffspring nuclear families separately and the phenotypes of the parents were excluded from the QTDT; therefore, sex was not used as a covariate. Permutations (1000 simulations) were performed to generate empirical $P$ values to avoid false-positive results generated in multiple tests ${ }^{[7]}$. Statistical analysis was performed using SPSS version 11.0 (SPSS, Chicago, IL, USA). The $P$ values $<0.05$ were defined as nominally significant for all of the analyses. However, 3 genotypes were present in every SNP, and 3 phenotypes of BMD variation were used in this study; therefore, we adopted the most conserva- tive method (Bonferroni multiple-significance-test correction) to address the problem of multiple comparisons. As a result, the cutoff of significance was set at $P=0.05 / 9$ and the value was 0.0056 . Similarly, 4 haplotypes and 3 phenotypes of BMD variation were present in this study; therefore, the cutoff of significance was set at $P=0.05 / 12$ and the value was 0.0042 .

\section{Results}

\section{Allele frequencies and haplotype structure}

Genotype data from unrelated parents of each nuclear family were used to calculate allele frequencies. We used 1602 unrelated parents of both male- and female-offspring nuclear families to calculate the MAF of the 3 tagging SNPs in our study. The MAFs of rs1867863 and rs4972504 were 0.366 and 0.280 , respectively. Also, we found only the CC genotype in rs13418078 in our study (Table 1); therefore, we excluded rs13418078 from subsequent statistical analyses. The genotype frequencies of the remaining two SNPs did not deviate from Hardy-Weinberg equilibrium $(P>0.05)$. The frequencies of each SNP are shown in Table 2. On the basis of these polymorphisms, we inferred that four different haplotypes were present in our study population (Table 2). The most common haplotype, AC, had frequencies of $64.0 \%$ and $61.6 \%$ in maleand female-offspring nuclear families, respectively. The two most common haplotypes (AC and CT) accounted for 91.1\% and $89.2 \%$ of the total sample in male- and female-offspring nuclear families, respectively. According to these genotype frequencies for unrelated parents, rs1867863 and rs4972504 were in strong LD in both male- $\left(\mathrm{D}^{\prime}=0.98, r^{2}=0.65\right)$ and female$\left(\mathrm{D}^{\prime}=0.94, r^{2}=0.59\right)$ offspring nuclear families.

\section{Association between peak BMD and SNPs in male-offspring nuclear families}

The basic characteristics of the sons are summarized in Table 3 . The average age of the men was $30.4 \pm 6.1$ years, which corresponds to the age when peak BMD is achieved in Chinese men $^{[27]}$. The heritability of lumbar spine, femoral neck and total hip BMD was 56\%,70\%, and 69\%, respectively. Table 4 presents a summary of the results of the QTDT analyses of male-offspring nuclear families. There were 280 and 252 informative nuclear families for the TDT analysis at rs1867863 and rs4972504, respectively. The within-family association between rs1867863 and femoral neck BMD $(P=0.044)$ and the within-family association between rs4972504 and femoral neck and total hip BMD ( $P=0.047$ and $P=0.036$, respectively) were significant at the 0.05 level but not significant at the

Table 1. HOXD4 SNPs analyzed in this study.

\begin{tabular}{|c|c|c|c|c|c|}
\hline $\begin{array}{l}\text { Tagging SNPs } \\
\text { in dbSNP }\end{array}$ & Position & $\begin{array}{c}5^{\prime} \text { near sequence } \\
20 \text { bases }\end{array}$ & SNP & $\begin{array}{c}3 \text { ' near sequence } \\
20 \text { bases }\end{array}$ & $\begin{array}{l}\text { MAF in Chinese } \\
\text { population } \\
\text { (in this study) }\end{array}$ \\
\hline rs1867863 & $5^{\prime}$ near gene & TGCCGGCCCCAATCTCTTCC & $\mathrm{A} / \mathrm{C}$ & ACCGTTCGACGCAGCCACCC & 0.366 \\
\hline rs13418078 & $5^{\prime}$ near gene & GTGACCCTGATGAAGACAAA & $\mathrm{C} / \mathrm{T}$ & GGCCTTTGTATGGCAGAATC & 0 \\
\hline rs4972504 & $3^{\prime}$ near gene & GCAGTGTTTTACAGGAATTA & $\mathrm{C} / \mathrm{T}$ & GTGTAGGGGAGGGGCTGTGC & 0.280 \\
\hline
\end{tabular}


Table 2. Frequencies of HOXD4 polymorphisms and of HOXD4 haplotypes in a Chinese population (unrelated parents of two nuclear families). Number of people is shown in parentheses.

\begin{tabular}{|c|c|c|c|c|}
\hline $\begin{array}{c}\text { SNP } \\
\text { in dbSNP }\end{array}$ & & $\begin{array}{l}\text { Male-offspring nuclear families } \\
\qquad n=800\end{array}$ & $\begin{array}{l}\text { Female-offspring nuclear families } \\
\qquad n=802\end{array}$ & $\begin{array}{c}\text { Total } \\
n=1602\end{array}$ \\
\hline \multirow[t]{3}{*}{ rs1867863 } & $\mathrm{AA}$ & $0.416(333)$ & $0.408(327)$ & $0.412(660)$ \\
\hline & $\mathrm{AC}$ & $0.452(362)$ & $0.436(350)$ & $0.444(712)$ \\
\hline & $\mathrm{CC}$ & $0.132(105)$ & $0.156(125)$ & $0.144(230)$ \\
\hline \multirow[t]{8}{*}{ rs4972504 } & $\mathrm{CC}$ & $0.521(417)$ & $0.522(419)$ & $0.522(836)$ \\
\hline & $\mathrm{CT}$ & $0.410(328)$ & $0.382(306)$ & $0.396(634)$ \\
\hline & $\mathrm{TT}$ & $0.069(55)$ & $0.096(77)$ & $0.082(132)$ \\
\hline & Haplotype allele & & & \\
\hline & $\mathrm{AC}$ & 0.6395 (1023) & 0.6155 (989) & $0.6280(2012)$ \\
\hline & AT & $0.0027(4)$ & $0.0104(15)$ & $0.0059(19)$ \\
\hline & $\mathrm{CC}$ & 0.0865 (138) & 0.0977 (155) & $0.0914(293)$ \\
\hline & $\mathrm{CT}$ & $0.2713(435)$ & $0.2763(445)$ & $0.2747(880)$ \\
\hline
\end{tabular}

Table 3. Characteristics of the 415 male offspring classified according to HOXD4 genotype. Values are means \pm SD.

\begin{tabular}{|c|c|c|c|c|c|c|c|}
\hline & \multicolumn{3}{|c|}{ rs1867863 } & \multicolumn{3}{|c|}{ rs4972504 } & \multirow{2}{*}{ Total (range) } \\
\hline & AA & $\mathrm{AC}$ & $\mathrm{CC}$ & $\mathrm{CC}$ & CT & $\mathrm{TT}$ & \\
\hline$n$ & 180 & 186 & 49 & 228 & 160 & 27 & 415 \\
\hline Age (years) & $30.8 \pm 6.3$ & $30.2 \pm 6.0$ & $29.3 \pm 5.4$ & $30.9 \pm 6.1$ & $29.9 \pm 6.1$ & $28.9 \pm 4.9$ & $\begin{array}{c}30.4 \pm 6.1 \\
(18.3-44.4)\end{array}$ \\
\hline Height (cm) & $172.9 \pm 6.2$ & $172.7 \pm 6.0$ & $173.7 \pm 4.6$ & $173.0 \pm 5.9$ & $172.8 \pm 6.1$ & $172.8 \pm 4.4$ & $\begin{array}{l}172.9 \pm 5.9 \\
(159.0-190.0)\end{array}$ \\
\hline Weight (kg) & $69.7 \pm 10.1$ & $71.0 \pm 11.1$ & $73.0 \pm 11.7$ & $69.8 \pm 9.9$ & $71.4 \pm 11.9$ & $74.1 \pm 10.5$ & $\begin{array}{l}70.7 \pm 10.8 \\
(50.0-110.0)\end{array}$ \\
\hline Lumbar spine BMD $\left(\mathrm{g} / \mathrm{cm}^{2}\right)$ & $1.139 \pm 0.137$ & $1.139 \pm 0.139$ & $1.134 \pm 0.132$ & $1.143 \pm 0.137$ & $1.128 \pm 0.135$ & $1.157 \pm 0.150$ & $\begin{array}{c}1.138 \pm 0.137 \\
(0.855-1.518)\end{array}$ \\
\hline Femoral neck BMD $\left(\mathrm{g} / \mathrm{cm}^{2}\right)$ & $1.001 \pm 0.143$ & $0.996 \pm 0.141$ & $0.992 \pm 0.149$ & $0.997 \pm 0.141$ & $0.996 \pm 0.147$ & $1.014 \pm 0.138$ & $\begin{array}{c}0.998 \pm 0.143 \\
(0.637-1.473)\end{array}$ \\
\hline Total hip BMD $\left(\mathrm{g} / \mathrm{cm}^{2}\right)$ & $1.018 \pm 0.139$ & $1.010 \pm 0.134$ & $1.019 \pm 0.145$ & $1.015 \pm 0.138$ & $1.012 \pm 0.135$ & $1.030 \pm 0.146$ & $\begin{array}{c}1.015 \pm 0.137 \\
(0.701-1.404)\end{array}$ \\
\hline
\end{tabular}

strictest level (0.0056). We observed an association between haplotypes and peak BMD using QTDT (Table 5). Also, 291, 4, 116, and 260 informative families were present for the TDT analysis at hapotype 1 (AC), 2 (AT), 3 (CC), and 4 (CT), respectively. The frequency of haplotype 2 (AT) was small so it was not tested in the population stratification and withinfamily association. No significant evidence was found among any haplotypes and BMD at any bone site at the strictest level (0.0042). Therefore, no population stratification was found for single SNPs or haplotypes in male-offspring nuclear families, and no single SNP or haplotypes showed significant evidence of association (including within-family association and total association) with peak BMD in the lumbar spine or hip. With regard to multiple-parameter tests, we performed 1000 permutation tests to improve fidelity. Subsequent permutations were in agreement with these results.

\section{Association between peak BMD and SNPs in female-offspring} nuclear families

The basic characteristics of the daughters are summarized in
Table 6. The average age of the daughters analyzed in the study was $31.4 \pm 5.8$ years. The heritability of spine, femoral neck and total hip BMD varied from $60 \%$ to $80 \%$. Table 4 presents a summary of the results of the QTDT analyses of female-offspring nuclear families. There were 311 and 280 informative nuclear families for the TDT analysis at rs1867863 and rs4972504, respectively. No population stratification was identified at any of the skeletal sites investigated in this study population. We failed to find a significant total and withinfamily association between these 2 SNPs and peak BMD at any bone site. We observed the association between haplotypes and peak BMD using QTDT (Table 5). There were 314, 16, 145, and 275 informative families for the TDT analysis at hapotype 1 (AC), 2 (AT), 3 (CC), and 4 (CT), respectively. The frequency of haplotype 2 (AT) was small so it was not tested in population stratification and within-family association. No significant evidence was found among any haplotypes and BMD at any bone site (Table 5).

Using linkage tests alone and in combination with models of association, we did not observe significant results for a linkage 
Table 4. $P$ values of SNPs for male- and female-offspring nuclear families population stratification, total association, and within-family association using QTDT. BMD values are adjusted for age, height and weight; the cutoff of significance was set at $P=0.0042$.

\begin{tabular}{|c|c|c|c|c|}
\hline & $\begin{array}{r}\text { Male-of } \\
\text { fam } \\
\text { rs1867863 }\end{array}$ & $\begin{array}{l}\text { pring } \\
\text { es } \\
\text { s4972504 }\end{array}$ & $\begin{array}{r}\text { Female-c } \\
\text { fami } \\
\text { s1867863 }\end{array}$ & $\begin{array}{l}\text { spring } \\
\text { s } \\
4972504\end{array}$ \\
\hline \multicolumn{5}{|c|}{ Tests of population stratification } \\
\hline Lumbar spine BMD & 0.316 & 0.276 & 0.962 & 0.397 \\
\hline Femoral neck BMD & 0.025 & 0.023 & 0.977 & 0.331 \\
\hline Total hip BMD & 0.047 & 0.024 & 0.912 & 0.381 \\
\hline \multicolumn{5}{|c|}{ Tests of total association } \\
\hline Lumbar spine BMD & 0.635 & 0.365 & 0.787 & 0.566 \\
\hline Femoral neck BMD & 0.948 & 0.970 & 0.968 & 0.517 \\
\hline Total hip BMD & 0.687 & 0.780 & 0.833 & 0.379 \\
\hline \multicolumn{5}{|c|}{ Tests of within-family association } \\
\hline Lumbar spine BMD & 0.268 & 0.164 & 0.927 & 0.308 \\
\hline Femoral neck BMD & 0.044 & 0.047 & 0.964 & 0.244 \\
\hline Total hip BMD & 0.053 & 0.036 & 0.989 & 0.229 \\
\hline \multicolumn{5}{|c|}{$P 1000$ permutation of within-family association } \\
\hline Lumbar spine BMD & 0.237 & 0.097 & 0.903 & 0.190 \\
\hline Femoral neck BMD & 0.039 & 0.036 & 0.951 & 0.195 \\
\hline Total hip BMD & 0.049 & 0.031 & 0.991 & 0.143 \\
\hline
\end{tabular}

between each SNP or haplotype and BMD in either male- or female-offspring nuclear families (data not shown). Finally, based on our power calculation, both male- and female-off- spring nuclear families had more than $80 \%$ power to detect the HOXD4 gene as a QTL, which can explain approximately $10 \%$ of bone phenotype variation.

\section{Discussion}

In this study, we measured 3 tagging SNPs in the HOXD4 gene and found that the distribution frequencies of these SNPs in the Chinese Han population differed from the distributions in other populations. We found the MAF of rs1867863 and rs4972504 (0.366 and 0.280) in our study were between the European population $(0.353$ and 0.308$)$ and the Japanese population (0.375 and 0.205$)$ according to the NCBI website (http:/ / www.ncbi.nlm.nih.gov/ projects/SNP/snp_ref. cgi?rs=1867863; http:/ / hapmap.ncbi.nlm.nih.gov/cgi-perl/ snp_details_B36?name=rs4972504\&source=hapmap24_B36). For rs13418078, we found only the CC genotype and not the TT or CT genotype, though rs13418078 had a MAF of $>10 \%$ in Japanese subjects (http://www.ncbi.nlm.nih.gov/projects / SNP/snp_ref.cgi?rs=13418078). We used a relatively large sample composed of 1602 unrelated Han Chinese to calculate the allele frequencies; therefore, our results are credible. According to these genotypes frequencies, rs1867863 and rs4972504 were in strong LD in our population.

Peak bone mass is a major determinant of the risk of osteoporosis, and clear evidence demonstrates that peak bone mass has strong genetic determination with heritability of more than $50 \%{ }^{[28]}$. The heritability of lumbar spine and hip BMD in our population was also above $50 \%$. This study tested the linkage and association of the HOXD4 gene and BMD in two cohorts of Chinese nuclear families. We failed to find a significant association between the 2 SNPs or haplotypes of the

Table 5. $P$ values of haplotypes for male- and female-offspring nuclear families population stratification, total association, and within-family association using QTDT. BMD values are adjusted for age, height and weight; the cutoff of significance was set at $P=0.0042$.

\begin{tabular}{|c|c|c|c|c|c|c|c|c|}
\hline \multirow[b]{2}{*}{ Haplotype allele } & \multicolumn{4}{|c|}{ Male-offspring families } & \multicolumn{4}{|c|}{ Female-offspring families } \\
\hline & $A C$ & AT & $\mathrm{CC}$ & CT & $\mathrm{AC}$ & AT & $\mathrm{CC}$ & CT \\
\hline \multicolumn{9}{|c|}{ Tests of population stratification } \\
\hline Lumbar spine BMD & 0.255 & & 0.911 & 0.315 & 0.991 & & 0.181 & 0.398 \\
\hline Femoral neck BMD & 0.021 & & 0.567 & 0.045 & 0.906 & & 0.194 & 0.404 \\
\hline Total hip BMD & 0.045 & & 0.726 & 0.062 & 0.765 & & 0.370 & 0.487 \\
\hline \multicolumn{9}{|c|}{ Tests of total association } \\
\hline Lumbar spine BMD & 0.679 & 0.250 & 0.611 & 0.361 & 0.840 & 0.017 & 0.754 & 0.954 \\
\hline Femoral neck BMD & 0.927 & 0.038 & 0.934 & 0.864 & 0.739 & 0.139 & 0.672 & 0.734 \\
\hline Total hip BMD & 0.869 & 0.022 & 0.923 & 0.623 & 0.988 & 0.185 & 0.190 & 0.568 \\
\hline \multicolumn{9}{|c|}{ Tests of within-family association } \\
\hline Lumbar spine BMD & 0.231 & & 0.898 & 0.185 & 0.925 & & 0.187 & 0.480 \\
\hline Femoral neck BMD & 0.046 & & 0.628 & 0.066 & 0.789 & & 0.180 & 0.372 \\
\hline Total hip BMD & 0.070 & & 0.782 & 0.063 & 0.804 & & 0.150 & 0.374 \\
\hline \multicolumn{9}{|c|}{ P 1000 permutation of within-family association } \\
\hline Lumbar spine BMD & 0.195 & & 0.885 & 0.133 & 0.911 & & 0.077 & 0.379 \\
\hline Femoral neck BMD & 0.037 & & 0.633 & 0.053 & 0.764 & & 0.212 & 0.349 \\
\hline Total hip BMD & 0.066 & & 0.774 & 0.057 & 0.778 & & 0.132 & 0.304 \\
\hline
\end{tabular}


Table 6. Characteristics of the 458 female offspring classified according to HOXD4 genotype. Values are means \pm SD.

\begin{tabular}{|c|c|c|c|c|c|c|c|}
\hline & \multicolumn{3}{|c|}{ rs1867863 } & \multicolumn{3}{|c|}{ rs4972504 } & \multirow[t]{2}{*}{ Total (range) } \\
\hline & AA & $\mathrm{AC}$ & $\mathrm{CC}$ & $\mathrm{CC}$ & CT & TT & \\
\hline$n$ & 183 & 209 & 66 & 222 & 201 & 35 & 458 \\
\hline Age (years) & $32.0 \pm 5.7$ & $31.0 \pm 5.9$ & $30.8 \pm 5.6$ & $31.7 \pm 5.8$ & $31.1 \pm 5.8$ & $30.9 \pm 5.7$ & $\begin{array}{l}31.4 \pm 5.8 \\
(19.3-44.4)\end{array}$ \\
\hline Height (cm) & $160.1 \pm 4.6$ & $159.7 \pm 5.7$ & $159.8 \pm 5.1$ & $160.1 \pm 4.8$ & $159.6 \pm 5.6$ & $159.7 \pm 4.4$ & $\begin{array}{l}159.8 \pm 5.2 \\
(142.0-172.5)\end{array}$ \\
\hline Weight (kg) & $55.5 \pm 8.0$ & $54.4 \pm 8.0$ & $55.0 \pm 8.0$ & $55.2 \pm 8.5$ & $54.8 \pm 7.6$ & $55.3 \pm 6.7$ & $\begin{array}{r}55.1 \pm 8.0 \\
(38.0-87)\end{array}$ \\
\hline Lumbar spine BMD $\left(\mathrm{g} / \mathrm{cm}^{2}\right)$ & $0.970 \pm 0.102$ & $0.950 \pm 0.099$ & $0.966 \pm 0.113$ & $0.963 \pm 0.102$ & $0.959 \pm 0.100$ & $0.953 \pm 0.116$ & $\begin{array}{c}0.960 \pm 0.102 \\
(0.705-1.288)\end{array}$ \\
\hline Femoral neck BMD $\left(\mathrm{g} / \mathrm{cm}^{2}\right)$ & $0.774 \pm 0.111$ & $0.775 \pm 0.107$ & $0.786 \pm 0.010$ & $0.772 \pm 0.120$ & $0.782 \pm 0.109$ & $0.773 \pm 0.083$ & $\begin{array}{c}0.776 \pm 0.107 \\
(0.484-1.130)\end{array}$ \\
\hline Total hip BMD (g/ $\left.\mathrm{cm}^{2}\right)$ & $0.855 \pm 0.114$ & $0.851 \pm 0.106$ & $0.868 \pm 0.101$ & $0.851 \pm 0.111$ & $0.859 \pm 0.107$ & $0.858 \pm 0.099$ & $\begin{array}{c}0.855 \pm 0.108 \\
(0.501-1.170)\end{array}$ \\
\hline
\end{tabular}

HOXD4 gene and peak BMD at any bone site in either maleor female-offspring families. Both male- and female-offspring nuclear families offered more than $80 \%$ power in testing a candidate gene as a QTL, which explains the approximately $10 \%$ of BMD variation. In our previous study, we showed that genetic polymorphisms in myostatin likely affect peak BMD variation in female-offspring nuclear families ${ }^{[7]}$. Therefore, the negative results of this study are most likely not caused by sample selection. Population stratification may lead to false-negative or false-positive results in regular population analyses $^{[29]}$; however, because the within-family association in QTDT is implemented through a transmission disequilibrium test, it is not influenced by population stratification ${ }^{[21]}$. Consequently, the results of the within-family association test through QTDT are robust regarding population stratification and sample heterogeneity ${ }^{[16]}$. Moreover, we performed 1000 permutations to eliminate false-positive results. Specifically, 280 male-offspring nuclear families and 311 female-offspring nuclear families with at least one heterozygous parent were used for the TDT analysis at rs1867863, and these numbers were 252 male-offspring nuclear families and 280 female-offspring nuclear families for rs4972504. With greater heterozygosity, more information can be derived from families in the QTDT analysis. Thus, the possibility of false-negative findings in our study was minimized, and the results of the QTDT in our study are valid and persuasive.

HOX proteins play an important role in the BMP pathway ${ }^{[10]}$. The BMPs are a large family of secreted ligands within the TGF $\beta$ superfamily that play essential roles in embryonic development ${ }^{[30]}$. BMP-2 can promote osteogenic differentiation of adult mesenchymal stem cells and it was able to reverse the osteopenic phenotype in the bones of mice ${ }^{[31]}$. In response to $\mathrm{BMP}$, the Smad1/4 complex interacts with the DNA-binding domain of HOXC8 and dislodges it from the osteopontin promoter element, which initiates gene transcription and induces osteoblast differentiation $^{[32]}$. Similar interactions between Smads and most HOXD proteins suggest potential roles of
HOXD as transcription factors downstream of BMP ${ }^{[33]}$. Therefore, we assumed that HOXD4 may affect the BMP pathway in a similar manner as HOXC8. However, our study failed to show that genetic polymorphisms in HOXD4 are a major contributor to the variation of peak BMD in either men or women. Furthermore, sons and daughters in our study represented only subjects who had reached peak BMD; therefore, further studies will be necessary to determine if HOXD4 plays a role in bone loss. The biological roles of these polymorphisms should be revealed by future functional studies.

Our study has several strengths. First, our subjects included two cohorts of nuclear families illustrating the peak BMD of both men and women, which made our study more credible. Second, the sample size was relatively large. Third, we investigated all three tagging SNPs of the HOXD4 gene. The study has limitations as well. As our previous studies mentioned $^{[7,16,17]}$, both nuclear families contained few sibling pairs, and we did not detect any linkage for these SNPs and haplotypes in HOXD4 with BMD in the hip.

In conclusion, this analysis is to investigate the relationship between tagging SNPs and haplotypes in HOXD4 and peak BMD in humans. We failed to find significant within-family association among these SNPs, haplotypes and peak BMD at any bone site in either male- or female-offspring nuclear families. These findings suggest the genetic polymorphisms in HOXD4 may not be a major contributor to the observed variability in peak BMD in either the lumbar spine or the hip in Chinese men and women. Confirmation of our results in other populations is required, and further functional research is needed to investigate the mechanism of the effect of HOXD4 on bone growth.

\section{Acknowledgements}

The study was supported by the National Natural Science Foundation of China (NSFC) (No 30570891, 30771019, and 30800387) and Program of Shanghai Chief Scientist (No 08XD1403000). 


\section{Author contribution}

Zhen-lin ZHANG designed the research; Hao ZHANG, Jinwei HE, Gao GAO, and Wen-zhen FU performed the research; Hua YUE, Jin-bo YU, Wei-wei HU, Jie-mei GU, Yun-qiu HU, Miao LI, and Yu-juan LIU recruited the subjects; and Hao ZHANG and Zhen-lin ZHANG wrote the paper.

\section{References}

1 Miller PD, Siris ES, Barrett-Connor E, Faulkner KG, Wehren LE, Abbott TA, et al. Prediction of fracture risk in postmenopausal white women with peripheral bone densitometry: evidence from the National Osteoporosis Risk Assessment. J Bone Miner Res 2002; 17: 2222 30.

2 Brown LB, Streeten EA, Shapiro JR, McBride D, Shuldiner AR, Peyser $\mathrm{PA}$, et al. Genetic and environmental influences on bone mineral density in pre- and post-menopausal women. Osteoporos Int 2005; 16: 1849-56.

3 Flicker L, Hopper JL, Rodgers L, Kaymakci B, Green RM, Wark JD. Bone density determinants in elderly women: a twin study. J Bone Miner Res 1995; 10: 1607-13.

4 Ralston SH, Galwey N, MacKay I, Albagha OM, Cardon L, Comnston JE, et al. Loci for regulation of bone mineral density in men and women identified by genome wide linkage scan: The FAMOS study. Hum Mol Genet 2005; 14: 943-51.

5 Styrkarsdottir U, Halldorsson BV, Gretarsdottir S, Gudbjartsson DF, Walters GB, Ingvarsson T, et al. Multiple genetic loci for bone mineral density and fractures. N Engl J Med 2008; 358: 2355-65.

6 Xiao P, Shen H, Guo YF, Xiong DH, Liu YZ, Liu YJ, et al. Genomic regions identified for $B M D$ in a large sample including epistatic interactions and gender-specific effects. J Bone Miner Res 2006; 21: 1536-44.

7 Zhang ZL, He JW, Qin YJ, Hu YQ, Li M, Zhang H, et al. Association between myostatin gene polymorphisms and peak BMD variation in Chinese nuclear families. Osteoporos Int 2008; 19: 39-47.

8 Dlugaszewska B, Silahtaroglu A, Menzel C, Kübart S, Cohen M, Mundlos S, et al. Breakpoints around the HOXD cluster result in various limb malformations. J Med Genet 2006; 43: 111-8.

9 Shi X, Yang X, Chen D, Chang Z, Cao X. Smad1 interacts with homeobox DNA-binding proteins in bone morphogenetic protein signaling. J Biol Chem 1999; 274: 13711-7.

10 Li X, Cao X. BMP signaling and skeletogenesis. Ann N Y Acad Sci 2006; 1068: 26-40.

11 Liu Z, Shi W, Ji X, Sun C, Jee WS, Wu Y, et al. Molecules mimicking Smad1 interacting with HOX stimulate bone formation. J Biol Chem 2004; 279: 11313-9

12 Kappen C, Mello MA, Finnell RH, Salbaum JM. Folate modulates HOXD gene-controlled skeletal phenotypes. Genesis 2004; 39: 15566.

13 Oliver G, Sidell N, Fiske W, Heinzmann C, Mohandas T, Sparkes RS, et al. Complementary homeo protein gradients in developing limb buds. Genes Dev 1989; 3: 641-50.

14 Mavilio F, Simeone A, Giampaolo A, Faiella A, Zappavigna V, Acampora $D$, et al. Differential and stage-related expression in embryonic tissues of a new human homoeobox gene. Nature 1986; 324: 664-8.

15 van Scherpenzeel Thim V, Remacle S, Picard J, Cornu G, Gofflot F, Rezsohazy R, et al. Mutation analysis of the HOXD paralogous 4-13 genes in children with acute lymphoid malignancies: identification of a novel germline mutation of HOXD4 leading to a partial loss of function. Human Mutation 2005; 25: 384-95.

16 Qin YJ, Shen H, Huang QR, Zhao LJ, Zhou Q, Li MX, et al. Estrogen receptor alpha gene polymorphisms and peak bone density in Chinese nuclear families. J Bone Miner Res 2003; 18: 1028-35.

17 Zhang ZL, He JW, Qin YJ, Hu YQ, Li M, Liu YJ, et al. Association between SNP and haplotypes in PPARGC1 and adiponectin genes and bone mineral density in Chinese nuclear families. Acta Pharmacol Sin 2007; 28: 287-95.

18 Liu XH, Liu YJ, Jiang DK, Li YM, Li MX, Qin YJ, et al. No evidence for linkage and/or association of human alpha2-HS glycoprotein gene with bone mineral density variation in Chinese nuclear families. Calcif Tissue Int 2003; 73: 244-50.

19 Urano T, Shiraki M, Ezura Y, Fujita M, Sekine E, Hoshino S, et al. Association of a single-nucleotide polymorphism in low-density lipoprotein receptor-related protein 5 gene with bone mineral density. J Bone Miner Metab 2004; 22: 341-5.

20 Peacock M, Koller DL, Fishburn T, Krishnan S, Lai D, Hui S, et al. Sex-specific and non-sex-specific quantitative trait loci contribute to normal variation in bone mineral density in men. J Clin Endocrinol Metab 2005; 90: 3060-6.

21 Abecasis GR, Cookson WO, Cardon LR. Pedigree tests of transmission disequilibrium. Eur J Hum Genet 2000; 8: 545-51.

22 Gao G, Zhang ZL, Zhang H, Hu WW, Huang QR, Lu JH, et al. Hip axis length changes in 10554 males and females and the association with femoral neck fracture. J Clin Densitom 2008; 11: 360-6.

23 Barrett JC, Fry B, Maller J, Daly MJ. Haploviw: analysis and visualization of LD and haplotype maps. Bioinformatics 2005; 21: 263-5.

24 Stephens M, Smith NJ, Donnelly P. A new statistical method for haplotype reconstruction from population data. Am J Hum Genet 2001; 68: 978-89.

25 Abecasis GR, Cardon LR, Cookson WO. A general test of association for quantitative traits in nuclear families. Am J Hum Genet 2000; 66: 279-92.

26 Fulker DW, Cherny SS, Sham PC, Hewitt JK. Combined linkage and association sib-pair analysis for quantitative traits. Am J Hum Genet 1999; 64: 259-67.

27 Zhang ZL, Qin YJ, Huang QR, Hu YQ, Li M, He JW, et al. Bone minera density of the spine and femur in healthy Chinese men. Asian J Androl 2006; 8: 419-27.

28 McGuigan FE, Murray L, Gallagher A, Davey-Smith G, Neville CE, Van't Hof R, et al. Genetic and environmental determinants of peak bone mass in young men and women. J Bone Miner Res 2002; 17: 1273-

29 Deng HW, Shen H, Xu FH, Deng HY, Conway T, Zhang HT, et al. Tests of linkage and/or association of genes for vitamin $D$ receptor, osteocalcin, and parathyroid hormone with bone mineral density. J Bone Miner Res 2002; 17: 678-86.

30 Hogan BL. Bone morphogenetic proteins in development. Curr Opin Genet Dev 1996; 6: 432-8.

31 Turgeman G, Zilberman Y, Zhou S, Kelly P, Moutsatsos IK, Kharode YP, et al. Systemically administered rhBMP-2 promotes MSC activity and reverses bone and cartilage loss in osteopenic mice. J Cell Biochem 2002; 86: 461-74.

32 Yang X, Ji X, Shi X, Cao X. Smad1 domains interacting with Hoxc-8 induce osteoblast differentiation. J Biol Chem 2000; 275: 1065-72.

33 Li X, Nie S, Chang C, Qiu T, Cao X. Smads oppose HOX transcriptional activities. Exp Cell Res 2006; 312: 854-64. 